\title{
Success and Failure of Cardiovascular Disease Prevention in Czech Republic Over the Past 30 Years. Czech Part of the EUROASPIRE I-IV Surveys
}

\author{
H. ROSOLOVÁ ${ }^{1}$, B. NUSSBAUMEROVÁ ${ }^{1}$, O. MAYER Jr. ${ }^{1}$, R. CÍFKOVÁ ${ }^{2}$, \\ J. BRUTHANS ${ }^{2}$, on behalf of Czech EUROASPIRE I-IV investigators
}

${ }^{1}$ Center of Preventive Cardiology, Second Department of Internal Medicine, Charles University, Medical Faculty in Pilsen and Faculty Hospital Pilsen, Czech Republic, ${ }^{2}$ Center for Cardiovascular Prevention, Charles University, First Faculty of Medicine and Thomayer Hospital, Prague, Czech Republic

Received November 3, 2016

Accepted January 10, 2017

\begin{abstract}
Summary
Cardiovascular (CV) mortality was reduced more than $50 \%$ in the Czech population at the turn of the century, due to an improvement of major CV risk factors in the general population, interventional procedures implemented into the treatment of acute coronary events, and new drugs (ACE inhibitors, statins etc.) for CV prevention (Czech MONICA and post-MONICA studies, 1985-2008). An insufficient level of preventive efforts is described in the Czech patients after acute coronary syndrome (Czech part of the EUROASPIRE studies, 1995-2013). Drug underdosing and wrong patients' compliance to life style and drug therapy recommendations represent two main reasons of this unsatisfactory situation. The residual vascular risk of patients with stable coronary heart disease (CHD) is still high due to a poor control of conventional risk factors on the one hand, and due to increasing weight and glucose metabolism abnormalities on the other hand. Patients with insulin resistance and glucose disorders have more frequently non-LDL-C dyslipidemia (atherogenic dyslipidemia), hypertriglyceridemic waist and high atherogenic index of plasma (AIP>0.24), i.e. markers of residual CV risk. Among others increased dose of statins and combined lipid modifying therapy should be implemented in patients with CHD, diabetes or metabolic syndrome.
\end{abstract}

\section{Key words}

Cardiovascular prevention • Coronary heart disease • Residual risk

\section{Corresponding author}

H. Rosolová, Center of Preventive Cardiology, 2nd Department of Internal Medicine, Faculty Hospital Pilsen, E. Beneše 13, 30599 Pilsen, Czech Republic. E-mail: rosolova@fnplzen.cz

\section{Success of cardiovascular disease prevention in the Czech general population}

Cardiovascular (CV) mortality, i.e. mortality of myocardial infarction and stroke, culminated in the year 1985 with a significant continuous decline thereafter. Cardiovascular mortality was reduced more than $50 \%$ during the last 30 years. Age-adjusted coronary heart disease (CHD) mortality rates in the Czech Republic decreased by $66.2 \%$ in men and $65.4 \%$ in women in the age group 25-74 years, representing 12,080 fewer CHD deaths in 2007. Changes in CHD risk factors explained approximately $52 \%$ of the total mortality decrease, and improvements in medical treatments approximately $43 \%$. Increases in body mass index and in diabetes prevalence had a negative impact, increasing CHD mortality by approximately $1 \%$ and $5 \%$, respectively (Bruthans et al. 2014). Instead of that success, the standardized CV mortality 385 males/100,000 and 251 females/100,000 in the year 2012 ranks the Czech Republic among the countries with high global CV risk (Czech Health Statistics Yearbook 2013).

The causes of described success of CV mortality 
are laying in the improvement of major CV risk factors in the general population on the one hand (primary preventive efforts) and interventional procedures (percutaneous coronary intervention /PCI/ and coronary artery bypass graft /CABG/) implemented into the treatment of acute coronary events, and new drugs for primary and secondary prevention on the other hand. The trends in major $\mathrm{CV}$ risk factors in a representative population sample of the Czech Republic was assessed in the epidemiological Czech MONICA (MONItoring trends and determinants in CArdiovascular disease) and Czech post-MONICA studies (Cífková et al. 2010). The favorable dietary changes (significant decrease of the consumption of food with a high content of saturated fat and an increase of the fruit and vegetables consumption) and introducing of new antihypertensive drugs and statins since the 90th participated in the significant reduction of total cholesterol; the mean decrease by about $0.9 \mathrm{mmol} / \mathrm{l}$ in both genders. While significant decline of mean of systolic and diastolic blood pressure (BP) and improved hypertension control were assessed in both genders, the prevalence of hypertension declined only in females. Quitting smoking in males could be partly associated with a rise of obesity prevalence. Obesity in females was stable (Table 1). Nevertheless a big potential persists in primary and also secondary preventive efforts in Czech cardiology.

Table 1. Development of the major risk factors between 1985 and 2007/8 in the Czech population (aged 25-64 years) (modified according to the Cífková et al. 2010).

\begin{tabular}{lccc}
\hline & $\mathbf{1 9 8 5}$ & $\mathbf{2 0 0 7 / 0 8}$ & p for trend \\
\hline Males & & & 0.001 \\
TC (mmol/l) & $6.21 \pm 1.29$ & $5.29 \pm 1.10$ & 0.001 \\
SBP (mm Hg) & $135.8 \pm 19.2$ & $132.5 \pm 17.3$ & 0.001 \\
DBP (mm Hg) & $85.9 \pm 11.0$ & $84.4 \pm 10.1$ & $\mathrm{~ns}$ \\
Prevalence of $\mathrm{AH}(\%)$ & 51.9 & 50.2 & 0.001 \\
Smoking (\%) & 45.0 & 30.5 & 0.001 \\
Obesity (\%) & 19.7 & 33.6 & 0.001 \\
Females & & & 0.001 \\
TC (mmol/l) & $6.18 \pm 1.26$ & $5.30 \pm 1.06$ & 0.001 \\
SBP (mm Hg) & $131.6 \pm 20.9$ & $126.7 \pm 19.2$ & 0.001 \\
DBP (mm Hg) & $82.5 \pm 11.3$ & $80.6 \pm 9.6$ & $\mathrm{~ns}$ \\
Prevalence of AH (\%) & 42.5 & 37.3 & $\mathrm{~ns}$ \\
Smoking (\%) & 23.9 & 23.3 & 30.1 \\
Obesity (\%) & 28.0 & & \\
\hline
\end{tabular}

TC - total cholesterol, SBP - systolic blood pressure, DBP - diastolic blood pressure, ns - statistically nonsignificant. Obesity: $\mathrm{BMI} \geq 30 \mathrm{~kg} / \mathrm{m}^{2}$.

\section{Secondary prevention in Czech patients with stable coronary heart disease is still insufficient}

An insufficient level of preventive efforts in Czech patients after acute coronary syndrome is well documented in the EUROASPIRE (European Action on Secondary and Primary Prevention by Intervention to Reduce Events) studies. EUROASPIRE are cross-sectional surveys, which have evaluated the implementation of European guidelines for cardiovascular disease (CVD) prevention in everyday clinical practice across Europe since 1995. The surveys were undertaken under the auspices of the European Society of Cardiology (ESC). Czech Republic has been included into the EUROASPIRE surveys from the very beginning thanks to two reasons: new opportunities after the "Velvet revolution" in 1989 paved the way to contacts and cooperation with the "outer world" on one hand, and the great effort of Jaroslav Simon from the Charles University, Medical Faculty in Pilsen on the other hand.

The first EUROASPIRE survey was performed 
between 1995 and 1996 in nine countries, followed by a second independent survey (1999-2000) involving 15 countries. Both of these surveys showed high rates of modifiable $\mathrm{CV}$ risk factors in patients with stable coronary heart disease (CHD) in all participating countries, as well as failure to achieve the recommended targets for all established risk factors in all patients. The third EUROASPIRE survey was performed in 2006-2007 in 22 countries; its results show that, despite similarities in medication exposure, women are less likely to achieve BP, LDL (low density lipoprotein)-cholesterol (C) and glycosylated hemoglobin (HbAlc) targets after a coronary event than men. This gap did not appear to narrow between 1994 and 2007. The critical role of lifestyle in secondary prevention, even within a few months after an acute coronary event, was demonstrated in the third EUROASPIRE survey. Adverse lifestyle trends among coronary patients such as higher smoking rates among younger females, increasing obesity and central obesity, and higher incidence of diabetes (Kotseva et al. 2009). David Wood (London), the principal investigator of EUROASPIRE, commented these results as a big disappointment; despite the existence of clear, evidence-based guidelines, their implementation in routine clinical care was considered absolutely unsatisfactory. Number of countries involved into the EUROASPIRE surveys increase continuously; and the fourth survey (2012-2013) was joint by a total of 25 countries (Kotseva et al. 2016). The Czech centers in Pilsen and Prague have participated in all these four surveys.

Table 2. Basic parameters of the Czech patients included into the EUROASPIRE studies (modified according to the Mayer Jr. et al. 2014).

\begin{tabular}{lccccc}
\hline & EA I & EA II & EA III & EA IV & p for trend \\
\hline & $1995 / 96$ & $1999 / 00$ & $2006 / 07$ & $2012 / 13$ \\
$n$ & 331 & 410 & 421 & 372 & \\
M/F (\%) & $71 / 29$ & $74 / 26$ & $81 / 19$ & $83 / 17$ & $<2 \pm 7$ \\
Age (year) & $59 \pm 8$ & $59 \pm 8$ & $60 \pm 7$ & $29.5 \pm 4.3$ & $<0.002$ \\
BMI (kg/m $\left.{ }^{2}\right)$ & $28.6 \pm 4.2$ & $29.5 \pm 4.6$ & $29.6 \pm 4.7$ & 22 & $\mathrm{~ns}$ \\
Smoking (\%) & 24 & 20 & 24 & 40 & 0.001 \\
Hypertension (\%) & 64 & 44 & 60 & 40 & 0.0001 \\
Hyperchol (\%) & 77 & 88 & 48 & 48 & 0.0001 \\
DM $(\%)$ & 23 & 25 & 45 & & \\
\hline
\end{tabular}

M - males, F - females, BMI - body mass index, EA - EUROASPIRE, hypertension - blood pressure $\geq 140 / 90 \mathrm{~mm} \mathrm{Hg}$, hyperchol hypercholesterolemia LDL $\geq 2.5 \mathrm{mmol} / \mathrm{l}, \mathrm{DM}$ - diabetes mellitus, according to personal history and/or fasting blood glucose $\geq 7 \mathrm{mmol} / \mathrm{l}$, ns - statistically nonsignificant.

A comparison of major and other $\mathrm{CV}$ risk factors control in all four Czech editions of the EUROASPIRE surveys were presented in many scientific papers written by Czech investigators from Pilsen and Prague. In each survey patients below 71 years of age with CHD were identified from hospital records and interviewed and examined 6 months after CABG, PCI or an acute coronary syndrome at the 2nd Department of Internal Medicine in Pilsen and Department of Preventive Cardiology of the Institute for Clinical and Experimental Medicine in Prague. Development of major risk factors control since EUROASPIRE I to IV of the patients is presented in Table 2. The majority of patients participated in these studies were treated by general practitioners or specialists in cardiology and general internal medicine in their place of residence. The reality, that $1 / 5$ of patients after an acute coronary event smoke, is a fact of life style intervention failure. Blood pressure control depends on the quality of BP measurement procedure; BP was measured automatically twice during one visit (average of two values was used), difference between BP devices was adjusted. Only about $50 \%$ of all hypertensive patients have achieved BP below 140/90 mm Hg. Laboratory methods used during the EUROASPIRE surveys was also adjusted. Cholesterol control was improving with an increasing statin use since the middle of the 90th (Table 3). Czech patients did not achieve the LDL-C $\leq 2.5 \mathrm{mmol} / 1$ in $48 \%$ resp. $40 \%$ in EUROASPIRE 
III resp. IV; LDL-C $\leq 1.8 \mathrm{mmol} / 1$ (recommended since the European guidelines 2011) was not achieved in $76 \%$ patients with stable CHD in EUROASPIRE IV. In comparison to the other European countries participating in EUROASPIRE IV, in average even $80.7 \%$ of all patients with CHD did not achieve target values of
LDL-C $<1.8 \mathrm{mmol} / 1$ at the time of interview (Reiner et al. 2016). Statin treatment was prescribed in the majority of Czech patients included into EUROASPIRE III and IV, but the most usual dose of any statin was only $20 \mathrm{mg}$ independently of various efficacy in the statin group (Table 4) (Mayer Jr. et al. 2014).

Table 3. Development of lipid modifying drug use in the EUROASPIRE studies (modified according to the Mayer Jr. et al. 2014).

\begin{tabular}{|c|c|c|c|c|c|}
\hline Lipid modifying drugs & EA I & EA II & EA III & EA IV & $\mathbf{p}$ \\
\hline & $1995 / 96$ & $1999 / 00$ & $2006 / 07$ & $2012 / 13$ & \\
\hline Statins & 7 & 39 & 80 & 88 & $* * *$ \\
\hline Statins + fibrates & 20 & 9 & 3.5 & 2.4 & ns \\
\hline Statins + ezetimibe & NA & NA & 2.1 & 1.9 & ns \\
\hline Fibrates/ezetimibe & NA & NA & 1.7 & 1.1 & ns \\
\hline Without drugs & NA & NA & 13 & 6 & ns \\
\hline
\end{tabular}

All data are in \%. EA - EUROASPIRE, NA - not available, $* * * p<0.001, n s-$ statistically nonsignificant.

Table 4. Dose of atorvastatin in Czech patients included into the EUROASPIRE III and IV (modified according to the Mayer Jr. et al. 2014).

\begin{tabular}{ccc}
\hline $\begin{array}{c}\text { Atorvastatin } \\
(\mathbf{m g})\end{array}$ & $\begin{array}{c}\text { EA III } \\
\mathbf{( \% )}\end{array}$ & $\begin{array}{c}\text { EA IV } \\
\mathbf{( \% )}\end{array}$ \\
\hline & $2006 / 07$ & $2012 / 13$ \\
0 & 15 & 7 \\
10 & 37 & 9 \\
$\mathbf{2 0}$ & $\mathbf{4 3}$ & $\mathbf{4 7}$ \\
40 & 5 & 34.5 \\
80 & 0 & 2.5 \\
\hline
\end{tabular}

All statin doses are done in equipotent atorvastatin dose:

Atorva $10=$ simva $20=$ fluva $40=$ rosuva 5

Atorva $20=\operatorname{simva} 40=$ fluva $80=$ rosuva 10

Atorva $40=$ simva $80=$ rosuva 20

Atorva $80=$ rosuva 40

There are two causes of unsatisfactory control of LDL-C and blood pressure among Czech patients with CHD: statin underdosing caused by a concern about statin intolerance and a poor compliance of patients to swallow pills.

\section{Drug underdosing}

is quite expanded phenomenon in the lifelong treatment of asymptomatic diseases such as hypertension, hypercholesterolemia, etc.; physicians are concerned about side effects, especially in statins, where primarily muscle problems seems to occur more frequently, than it was described in the clinical studies. The European Atherosclerosis Society (EAS) Consensus Panel overviews current understanding of the pathophysiology of statin-associated muscle symptoms (SAMS), and provides guidance for diagnosis and management of them (Stroes et al. 2015). Muscle symptoms are the main causes for statin non-adherence and/or discontinuation. Pain and weakness are the most frequent complains during statin therapy, but it is very difficult to distinguish them from other causes of muscle problems. The typical SAMS are usually symmetrical and proximal, and generally affect large muscle groups including the thighs, buttocks, calves, and back muscles. These problems occur early (within 4-6 weeks after starting statin therapy), but may still occur after many years of treatment. New symptoms may occur with an increase in statin dose or initiation of an interacting drug. The SAMS appear to be more frequent in physically active individuals. Statin-associated muscle symptoms often appear more promptly when patients are re-exposed to the same statin. The majority of SAMS are not accompanied by marked creatinine kinase (CK) elevation. The incidence of SAMS with CK elevations more than tenfold normal value (usually referred as myopathy) is approximately 1 per 10000 per year with a standard statin dose (e.g. simvastatin $40 \mathrm{mg}$ daily). Rhabdomyolysis is a severe form of muscle damage associated with very high CK levels with myoglobinemia 
and/or myoglobinuria with a concomitantly increased risk of renal failure. The incidence of rhabdomyolysis associated with statin therapy is 1 in 100000 per year. It is very time consuming to test if the SAMS are really associated with statin use. It is necessary to exclude secondary causes (especially hypothyroidism and other common myopathies such as polymyalgia rheumatica, or increased physical activity), and review the indication for statin use. It is recommended to try at least 2 different statins in various doses including intermittent use (e.g. twice a week). Absolute statin intolerance is relatively rare (around $5 \%$ ), but patients are often not willing to have any new try and refuse all statins in any doses. Then one has to try another type of lipid modifying drugs, which are, especially in monotherapy, not so cardioprotective such as statins in monotherapy or in combination with ezetimibe.

\section{Low compliance of patients to the treatment}

Except of drug underdosing one has to presume, that low compliance to the drugs (i.e. adherence to the everyday dose and persistence, i.e. to use the drug the whole life) is common in our patients. Compliance to statins, other lipid modifying drugs or antihypertensives is very poor, as was repeatedly published (Chapman et al. 2005). A lifelong medical therapy of chronic asymptomatic diseases is troublesome. About $90.4 \%$ of all European patients with CHD having participated in EUROASPIRE IV were on statin therapy at the time of discharge from the hospital, which decreased to $86 \%$ one year later. Only $37.6 \%$ of these patients were prescribed a high-intensity statin at discharge, which even decreased to $32.7 \%$ later. In only 6 countries (all of them high-income countries) the number of patients on a high-intensity statin therapy increased substantially after the hospital discharge. It is worrying that statin therapy was discontinued in $11.6 \%$ (Reiner et al. 2016). To motivate patients to a lifelong use of pills is very important but very time-consuming. This is a big approach for specialists in cardiology or internal medicine and general practitioners, who are responsible for secondary prevention in patients after acute coronary syndrome. Some contemporary patients decide themselves which drug to select and use according to their feeling or according to self-monitoring results, e.g. BP, glucose level etc. There is also a general disinclination to swallow pills, i.e. ,pills are chemical substances which are rather toxic". Medial exposure against, e.g. statins use, supports that negative trend very much. Why do people like more the negative information concerning drug treatment than the positive one?

Physicians should improve the patient compliance by setting a better relationship with patients. Partnership between the physician and his patients is a basic require to be successful in patients motivation to modify their lifestyle habits, to use drugs, to agree with the treatment process etc. The physician should inspire the confidence not only by his (her) arguments but especially by the strength of attitude to the patient. Professor Chaviar Amador (New York) is the founder of the L.E.A.P. (Listen-Empathize-Agree-Partner) system, which teaches the importance of strong relationships in everything, and also in treating illness. It is a procedure to learn how to listen to patients, to empathize their feelings, concerns etc., how to be in an agreement with patients, but not agree with their wrong opinions. The L.E.A.P. system learns how to become a partner with patient and then try to change their opinions, to solve their problems, eliminate their fear and persuade them about right opinions, e.g. opinion concerning everyday statin treatment etc. (Amador 2010). On the other hand high-quality drugs present another important condition for the favorable compliance of patients. All drugs for a lifelong use have to be effective, safe and without side effects. The dosage has to be easy, i.e. once a day, better fewer. A fixed combination of more substances represents a very good trend in the management of chronic diseases, such as CHD. Fixed combined drugs reduce the number of pills which is associated with better patients' compliance. All drugs for primary and secondary CVD prevention are available and economically accessible in our country.

\section{Residual cardiovascular risk}

It is very well known, that many patients with CHD who achieve target major risk factors values still experience additional vascular events. A meta-analysis of statin studies with more than 90,000 patients has shown that these patients with CHD and "around" target LDL-C values still experience vascular events because of the residual vascular risk due to other risk factors, especially non-LDL-C dyslipidemia (Baigent et al. 2005). Overweight or obesity with visceral adipose tissue accumulation, glucose metabolism disorders and dyslipidemia beyond LDL-C (especially high triglycerides /TG/ and/or low HDL-C) make up just an important part of the residual vascular risk (Fruchart et al. 2008). 
Sedentary lifestyle and high-calorie diet, features of lifestyle typical also for the Czech population, increase the incidence of overweight, obesity, and other metabolic disorders such as metabolic syndrome (MS) and type 2 diabetes mellitus (T2DM). We decided to look at some metabolic markers of residual vascular risk in the patients included into the EUROASPIRE studies I-IV. We found no significant difference in the prevalence of hypertriglyceridemic waist (33\% in EUROASPIRE I, $27-29 \%$ in EUROASPIRE II-IV), defined as $\mathrm{TG} \geq 2.0 \mathrm{mmol} / 1$ and waist circumference $\geq 90 \mathrm{~cm}$ in males and $\geq 85 \mathrm{~cm}$ in females (Lemieux et al. 2000). Atherogenic dyslipidemia (combination of $\mathrm{TG} \geq 2.0 \mathrm{mmol} / 1$ and HDL-C $\leq 1.0 \mathrm{mmol} / 1$ in males and $\leq 1.2 \mathrm{mmol} / 1$ in females) were slightly reduced during EUROASPIRE studies, but the target of non-HDL-C ( $=\mathrm{TC}-\mathrm{HDL}-\mathrm{C}<2.6 \mathrm{mmol} / \mathrm{l})$ was not achieved in the majority of patients with CHD. Non-HDL-C was significantly lower in EUROASPIRE III and IV in comparison with EUROASPIRE I and II, due mainly to the LDL-C decrease as TG and HDL-C concentrations were relatively stable in all groups of patients. The atherogenic index of plasma, $\mathrm{AIP}=\log [\mathrm{TG} / \mathrm{HDL}-\mathrm{C}]$, which is based on laboratory findings concerning the mechanism of regulation of the size of lipoproteins (Dobiasova and Fröhlich 2001) seems to be a very useful marker of residual vascular risk caused by atherogenic dyslipidemia (www.biomed.cas.cz/fgu/aip); high AIP $(>0.24)$ was documented in $21 \%$ patients with CHD in EUROASPIRE I and there were no obvious changes in the prevalence of increased AIP in both sexes in all EUROASPIREs. There was a steep increase in T2DM prevalence in both sexes in EUROASPIRE I-IV (from $23 \%$ to $48 \%$ ). The prevalence of hypertri-glyceridemic waist, atherogenic dyslipidemia, high non-HDL-C and, also high AIP were significantly higher in patients with T2DM or impaired fasting glucose as compared with patients with normal fasting glucose (Nussbaumerova et al. 2014).

Patients with CHD have a higher prevalence of glucose metabolism disorders than the general population, as shown in the Euro Heart Survey on Diabetes and the Heart with the Pilsen Center of Preventive Cardiology participating as a data collection center. Patients with acute coronary syndromes had impaired glucose tolerance in $36 \%$ and newly diagnosed DM in $22 \%$; these proportions were $38 \%$ and $14 \%$ in the group of stable CHD Patients (Bartnik et al. 2004). That is why the oral glucose tolerance test should be a routine procedure among CHD patients without known T2DM.

Shown in the paper by De Bacquer et al. (2013), the 5-year residual risk of $\mathrm{CV}$ mortality was assessed in patients participating in the EUROASPIRE I and II surveys. In multivariate analysis, smoking, total-C, and fasting glucose level have been shown to be the strongest independent modifiable predictors of CV mortality. In our analysis of Czech patients in EUROASPIRE studies I-IV, glucose level was in positive association with the metabolic markers of residual vascular risk.

All results of analyses among Czech patients with stable CHD (EUROASPIRE I-IV) show the unsatisfactory achievement of the recommended level of LDL-C, BP and nonsmoking on one hand, and presence of atherogenic dyslipidemia, characterized by small dense particles on the other hand; TG rich liproteins and their remnants are not fully susceptible to statin therapy. Fibrate use was reduced in patients with CHD in the last decades, with only about $1 \%$ of patients receiving fibrates in EUROASPIRE IV, although nearly half of all patients had T2DM. Physicians should think about prescribing fibrates especially in diabetic patients with overt atherogenic dyslipidemia $(\mathrm{TG} \geq 2.3 \mathrm{mmol} / \mathrm{l}$ and HDL-C $<0.9 \mathrm{mmol} / \mathrm{l}$ ), as demonstrated in the ACCORDlipid trial. Patients with T2DM and overt atherogenic dyslipidemia are at about $70 \%$ higher relative CV risk than diabetic patients without atherogenic dyslipidemia. Combination therapy with simvastatin plus fenofibrate reduced the relative risk of non-fatal CVD endpoints by about $30 \%$ (absolute risk of about $4.95 \%$ ) in comparison with simvastatin monotherapy (Ginsberg et al. 2010). In this context, beneficial effects of fenofibrate on microvascular complications in T2DM should be mentioned. The IMPROVE-IT study has shown recently, that combination of statin plus ezetimibe is also cardioprotective in patients with high $\mathrm{CV}$ risk and especially in diabetic patients (Cannon et al. 2015). The majority of Czech patients with stable CHD had higher LDL-C level than is recommended, but combination of statin with ezetimibe was used only in $1 \%$ patients! We will see in the ongoing EUROASPIRE V, which was done in the years 2015 and 2016, if the combination statin + ezetimibe would be more implemented for patients with CHD resp. with CHD and DM. The residual risk of patients with stable CHD is still high due to an unsatisfactory treatment of conventional risk factors on the one hand, and due to non-LDL-C dyslipidemia, particularly atherogenic dyslipidemia, especially in 
patients with glucose metabolism abnormalities, insulin resistance and hypertriglyceridemic waist, more accurately assessed by high AIP, on the other hand.

\section{Conclusion}

Except of a huge improvement of major CV risk factors in the Czech general population (reduced LDL-C and BP in both sexes and decreased smoking habit in males), improvement of invasive procedures in acute coronary events treatment and increasing prescription of statins, ACE inhibitors, beta-blockers, and antithrombotic drugs during the last 25 years, there is still a big potential for non-pharmacological approach and achieving recommended goals of major risk factors among patients in secondary $\mathrm{CV}$ prevention (Czech part of EUROASPIRE I-IV). Results concerning major CV risk factors of Czech patients included into the EUROASPIRE studies represent a major challenge for preventive approaches in patients with CHD and T2DM or MS treated by standard therapy. Increase dose of statins and combined lipid-modifying therapy (especially statin + ezetimibe or statin + fibrate) should be implemented in patients with CHD and/or T2DM or prediabetic status. It is generally accepted that there are still many challenges and approaches to be improved not only in the Czech Republic but also, throughout Europe countries to raise the standards of preventive cardiology.

Finally, we should like to remind you that Professor Jaroslav Simon, M.D., DrSc. (1930-2009) contributed very significantly to the development of
Czech Preventive Cardiology. He was the first Czech preventive cardiologist who became a member of the nucleus of ESC Working Group on Prevention and Epidemiology of CVD, later transformed into the European Association for Cardiovascular Prevention and Rehabilitation. He was involved in the development of the EUROASPIRE study design at the beginning of the nineties.

\section{Conflict of Interest}

There is no conflict of interest.

\section{Acknowledgements}

This summarizing article was supported by the grant of Ministry of Health of the Czech Republic - Conceptual Development of Research Organization (Faculty Hospital in Pilsen - FNPl, 00669806).

Thanks belong to all previous and current Czech investigators of EUROASPIRE studies I-IV in alphabetical order: *V. Adámková, *J. Bělohoubek, J. Filipovský, J. Jeschke, *M. Galovcová, P. Haman, J. Hrbková, **A. Krajčoviechová, *V. Lánská, M. Patraulea, *M. Pláškova, J. Mlíková Seidlerová, *Z. Škodová, K. Timoracká, P. Vagovičová, J. Vaněk and **P. Wohlfart, from: Charles University, Medical Faculty in Pilsen, 2nd Medical Department, Faculty Hospital Pilsen, *Department of Preventive Cardiology, Institute for Clinical and Experimental Medicine, Prague, **Center for Cardiovascular Prevention, Charles University in Prague, First Faculty of Medicine and Thomayer Hospital, Prague, Czech Republic.

\section{References}

AMADOR X: I Am Not Sick, I Don't Need Help. Vida Press, L.L.C., New York, 2010.

BAIGENT C, KEECH A, KEARNEY PM; ON BEHALF OF CHOLESTEROL TREATMENT TRIALISTS'(CTT) COLLABORATORS: Efficacy and safety of cholesterol-lowering treatment: prospective meta-analysis of data from 90,056 participants in 14 randomized trials of statins. Lancet 366: 1267-1278, 2005.

BARTNIK M, RYDÉN L, FERRARI R, MALMBERG K, PYÖRÄLÄ K, SIMMONS M, STAND E, SOLER J, ÖHRVIK J; ON BEHALF OF EURO HEART SURVEY INVESTIGATORS: The prevalence of abnormal glucose regulation in patients with coronary artery disease across Europe: The Euro Heart Survey on diabetes and the heart. Eur Heart J 25: 1880-1890, 2004.

BRUTHANS J, CÍFKOVÁ R, LÁNSKÁ V, O'FLAHERTY M, CRITCHLEY JA, HOLUB J, JANSKÝ P, ZVÁROVÁ J, CAPEWELL S: Explaining the decline in coronary heart disease mortality in the Czech Republic between 1985 and 2007. Eur J Prev Cardiol 21: 829-839, 2014.

CANNON CP, BLAZING MA, GIUGLIANO RP, MCCAGG A, WHITE JA, THEROUX P, DARIUS H, LEWIS BS, OPHUIS TO, JUKEMA JW, DE FERRARI GM, RUZYLLO W, DE LUCCA P, IM K, BOHULA EA, ET AL.: Ezetimibe added to statin therapy after acute coronary syndromes. $N$ Engl $J$ Med 372: 2387-2397, 2015. 
CHAPMAN RH, BENNER JS, PETRILLA AA, TIERCE JC, COLLINS SR, BATTLEMAN DS, SCHWARTZ JS: Predictors of adherence with antihypertensive and lipid-lowering therapy. Arch Intern Med 165: 1147-1152, 2005.

CÍFKOVÁ R, ŠKODOVÁ Z, BRUTHANS J, ADÁMKOVÁ V, JOZÍFOVÁ M, GALOVCOVÁ M, WOHLFAHRT P, KRAJČOVIECHOVÁ A, POLEDNE R, STÁVEK P, LÁNSKÁ V: Longitudinal trends in major cardiovascular risk factors in the Czech population between 1985 and 2007/8. Czech MONICA and Czech post-MONICA. Atherosclerosis 211: 676-681, 2010.

CZECH HEALTH STATISTICS YEARBOOKS: Health Information and Statistics Institute of the Czech Republic, 2013. http://www.uzis.cz/en/publications/czech-health-statistics-yearbook. Prague, 2013.

DE BACQUER D, DALlONGEVILlE J, KOTSEVA K, COONEY MT, PAJAK A, DECKERS JW, MAYER O, VANUZZO D, LEHTO S, FRAS Z, ÖSTOR E, AMBROSIO GB, DE BACKER G, WOOD D, KEIL U, SANS S, GRAHAM I, PYÖRÄLÄ K: Residual risk of cardiovascular mortality in patients with coronary heart disease: the EUROASPIRE risk categories. Int J Cardiol 168: 910-914, 2013.

DOBIÁŠOVÁ M, FRÖHLICH J: The plasma parameter log (TG/HDL-C) as an atherogenic index: correlation with lipoprotein particle size and esterification rate in Apo-B-lipoprotein-depleted plasma (FERHDL). Clin Biochem 34: 583-588, 2001.

FRUCHART JC, SACKS FM, HERMANS MP: The Residual Risk Reduction Initiative: a call to action to reduce residual vascular risk in dyslipidaemic patients. A condenset position paper by the Residual Risk Reduction Initiative (R3i). Diab Vasc Dis Res 5: 319-335, 2008.

GINSBERG HN, ELAM MB, LOVATO LC; ON BEHALF OF THE ACCORD STUDY GROUP: Effects of combination lipid therapy in type 2 diabetes mellitus. $N$ Engl J Med 362: 1563-1574, 2010.

KOTSEVA K, WOOD D, DE BACKER G, DE BACQUER D, PYÖRÄLÄ K, KEIL U; EUROASPIRE STUDY GROUP: Cardiovascular prevention guidelines in daily practice: a comparison of EUROASPIRE I, II, and III surveys in eight European countries. Lancet 373: 929-940, 2009

KOTSEVA K, WOOD D, DE BACQUER D, DE BACKER G, RYDÉN L, JENNINGS C, GYBERG V, AMOUYEL P, BRUTHANS J, CASTRO CONDE A, CÍFKOVÁ R, DECKERS JW, DE SUTTER J, DILIC M, DOLZHENKO M, ET AL.: EUROASPIRE IV: A European Society of Cardiology survey on the lifestyle, risk factor and therapeutic management of coronary patients from 24 European countries. Eur J Prev Cardiol 23: 636-648, 2016.

LEMIEUX A, PASCOT C, COUILLAR D: Hypertriglyceridemic waist: a marker of the atherogenic metabolic triad (hyperinsulinemia; hyperapolipoprotein B; small, dense LDL) in men? Circulation 102: 179-184, 2000.

MAYER O JR, BRUTHANS J, TIMORACKÁ K; ON BEHALF OF CZECH EUROASPIRE I-IV INVESTIGATORS: The changes in cardiovascular prevention practice between 1995 and 2012 in the Czech Republic. A comparison of EUROASPIRE I, II, III and IV study. Cor Vasa 56: e91-e97, 2014.

NUSSBAUMEROVÁ B, ROSOLOVÁ H, MAYER O, FILIPOVSKÝ J, CÍFKOVÁ R, BRUTHANS J: Residual cardiovascular risk in patients with stable coronary heart disease over the last 16 years (Czech part of the EUROASPIRE I-IV surveys). Cor Vasa 56: e98-e104, 2014.

REINER Ž, DE BACKER G, FRAS Z, KOTSEVA K, TOKGÖZOGLU L, WOOD D, DE BACQUER D; EUROASPIRE INVESTIGATORS: Lipid lowering drug therapy in patients with coronary heart disease from 24 European countries - findings from the EUROASPIRE IV survey. Atherosclerosis 246: 243-250, 2016.

STROES ES, THOMPSON PD, CORSIN A, VLADUTIU GD, RAAL FJ, RAY KK, RODEN M, STEIN E, TOKGÖZOĜLU L, NORDESTGAARD BG, BRUCKERT E, DE BACKER G, KRAUSS RM, LAUFS U, SANTOS RD, ET AL.: Statin-associated muscle symptoms: impact on statin therapy - European Atherosclerosis Society Consensus Panel Statement on Assessment, Aetiology and Management. Europ Heart J 36: 1012-1020, 2015. 